\title{
The Impact of Negative Reduction on Negative Question in Semantic
}

\section{Khalsiah*}

Faculty of Economic and Business, English Lecturers, University Malikusaleh Lhokseumawe Aceh Province, Indonesia

\author{
DOI: $10.36348 /$ SIJLL.2019.v02i09.001 \\ | Received: 25.10.2019 | Accepted: 02.11.2019| Published: 08.11.2019 \\ *Corresponding author: Khalsia

\section{Abstract}

The aim of this paper is to identify the impact of negative reductions on negative questions in English which have different meanings in linguistics; semantic meaning and interpretation meaning. Auxiliary and Modal auxiliary have an order available to control all negative questions and those have interpretation meaning of positive assumption and negative assumption in the sentences. The important elements are needed as substantial ability of English grammar that non-native is able to speak and write English correctly. The data obtained from audio-longitudinal recordings of samples; narrative stories, descriptions of images form of negative questions. The research purposes of this study are (1) to know impact of negative reductions on negative questions in semantic based on the developmental category found in sentences, and (2) to know the types of negative questions in semantic using negative reductions which are largely made by categories. The descriptive method used in this study was qualitative; the data was extracted from Corpus data, library research, and conclusions. The results of study show that negative reduction appeared in global forms of various types of negative questions in English, It had different relationships and functions of meaning. In context; negative reduction provided basic terminology which, within this framework, will allow the birth of explicit relationships in the interpretation of meaning. Negative questions have founded all the negative rhetorical questions, yes/no questions and Wh/ H question.

Keywords: Reduction, Negative question, Semantic.

Copyright @ 2019: This is an open-access article distributed under the terms of the Creative Commons Attribution license which permits unrestricted use, distribution, and reproduction in any medium for non-commercial use (NonCommercial, or CC-BY-NC) provided the original author and source are credited.

\section{INTRODUCTION}

Negative questions can be found in several types and forms of structure and daily conversation. Some conversational statements appear implicitly and explicitly, and indirectly form several negative interrogative categories and types which meaningfully produce positive and negative meaning forms, yes-no questions types, negative rhetorical questions that form positive meaning or to respond the sentence's answer is able marks a very specific mark. According to Quirk [1] verbs can be classified in two main types of lexical verbs and verbs. Negative question Auxiliaries can be defined as aid verbs because they do not have an independent existence as a verb phrase. To create verb phrases, negative question cannot be followed by the verb and marked with a negative note and the verb both of lexical and grammatical. It structurally requires a certain construction, in negative and question form generally (negative and interrogative). Although negative questions are not so much discussed, it may mention that specifically negative questions are sentences that often occur in everyday conversation both in rhetorical and other types.
Negative question is a sentence in English that has a function to inquire a thing commonly with negative form, also called negative interrogative sentences. This type of sentence is easy to identify with the characteristics of the auxiliary or modal auxiliary as a subject, Type of negative form "not' is placed after auxiliary and before the subject. Negative questions literally expect certain answers or to empathic effects in negative questions. this occurs before the production of affixes to Subversion-Aux Inversions is interrogative. Usage is gradually reduced due to correct construction. According to Corder [2], it's only natural that people make mistakes in learning and its excepted. It signals that it is on stage of internalizing the rule of the language. Several constructions are very crucial for the sentences; negative interrogative sentences are the important parts of English grammar that should be mastered as it appears in the sentence depends on the type of negative question: 
For Example:

1. isn't it raining? means I think it's raining, am I right?

The meaning of the sentence above is to express surprise at a piece of information. Similar to the above, but rather than saying "I think the answer is yes" You're saying "It's very surprising that the answer to this question is no!", and it allows the other person to confirm. Traditional grammar views -n't not as an inflectional suffix but as simply a phonologically reduced form (in traditional terms contracted) of the grammatical word not. According to this example, isn't is equivalent to non-contracted is + not, haven't $=$ have + not, doesn't $=$ does + not, etc. These contracted negative forms are, thus, equated with the reduced (contracted) forms of some of the other auxiliaries, namely are.

\section{Haven't you ever tried ice cream before?}

In this example, I am surprised that he has never tried ice cream, so I am not just asking the question, I am communicating that I will be very surprised if the answer is no. Learners are aware that mastering English, especially its structure is not easy. Constructing English sentence needs some important rules and it is not easy for some people, non-native who are learning English as Foreign Language. They should understand better the English grammar. In learning English, it is common that students make mistakes or errors both in spoken and written form. In natural communication, the positive, negative and interrogative form appear interchangeably. So, it is important for the learners to master the negative and interrogative form of the sentences. The learners need to have high capability of English grammar in order that they are able to speak and write correctly and grammatical

\section{LITERATURE REVIEW}

Quirk et al., [1] explained that verbs can be classified in two main types: lexical verbs and verbs. Auxiliaries can be defined as aid verbs because they do not have an independent existence as a verb phrase and how can explore the concept. They must be followed by a lexical verb and are structurally necessary for a particular construction, especially in negative form (negative and question (interrogative). Interrogative negatives derived from interrogatives have been described by experts such as Greenber [3], Quirk et al., [1], Celle [4], Klammer [5] and Downing [6]. The five experts divided some negative questions into different types, forms and meanings. These phrase structure adjunctions precede syntactic categorization, and as a result, during a subtle stage of English acquisition, children insert be forms (to be) and to do or as linguistic "dummies" to identify the functional category Complement. Modal auxiliary is undertaking they have a same as position in the negative question in English. Quirk et al., [1], explained about the division of
Negative question type is to find at yes-no, alternative, question and wh-questions

3a. Aren't you afraid?
3b. Are not you afraid?

Data in number (3a) is the type of full note and is found in formal or full contraction form and in data (3b) the analysis of the sentence data (3b) it is irrelevant form. Downing (2006) explains the inflectional form which is abbreviated with " $n$ 't" can be expressed in a semantic can be outside or inside meaning in negative deduction negative questions. Klammer [5] argued, that main verb is used after a joint research and interview. The writer discussed, and then distributed data. All of the data were chosen which coherence with types of negative question. Subject with a word-of-the-line auxiliary in the form of the negative function of the reduction. In the word of main verb functions to provide information that is able to distinguish the laboratory and therefore distinguish meaning and clarify additional information on the sentence given by the main verb. Negative reductions are supporting elements in negative questions 'not' form, and semantically have a declarative meaning and are found in a declarative interrogative form. This is very different from other experts. but the authors see a difference from a semantic angle. where negative questions are more semantic meaning to limit a question precisely.

Radford [7], for analyzing data, negative questions have different meanings in semantics and negative note occupiers in the form that have different interpretations and lexical forms: the constructions the non-thematic verb is seems to be a filler for functional information such as tense and agreement. The base position where they are generated, and is seems to be inserted in $I$, a position above $V$. This is form is different from the are form examples in (3a) in which are (copula/auxiliary) precedes negative and in interrogative sentences. According to this author, this occurs prior to the production of affix in morphology $[-\mathrm{s}, \quad-\mathrm{ed}]$ and prior to Subject-Aux Inversion in interrogatives. The use of is gradually decreases in favors of the correct constructions there after action:

Formula:

a. is (copula/auxiliary) + negation ++ Subject thematic verb (ing)

b. (modal can) + negation (n't) + Subject+ (bare) infinitive

What the present data reveal is that is (copula and auxiliary) is moved to a position higher than negation. And, as examples in (3a) and (3b) data a form of be (are) are inserted into a position negative aux- the sequence of subject very influences of negative aux- negative reduction its only interpretation the meaning. Therefore, the intensity in negative 
question and in negative reduction have a higher than verb, without cohesion meaning all sentence will be chaos. Patterns for these two types of constructions. In order to investigate further on are insertion constructions in negative question.

\section{RESEARCH METHODOLOGY}

This research used descriptive method of Djadja Sudharma [8]. He explained the use of descriptive and systematic method based on descriptive data and the nature of the relationship. This research is on consideration and in accordance with qualitative research. The focus of this research is aimed at negative questions based on supporting elements in negative reduction using auxiliary verb and auxiliary capital which have a positive meaning found in the form of interrogative negative supporting elements in negative questions in auxiliary verb and modal auxiliary. The research analysis method was in relation to the descriptive negative question form. The researcher calculated and analyzed the semantic is to find the source of the negative reduction can be identified and the follow-up can be organized. The research was conducted to representation of a better interpretation which was formally stated to imply the meaning in the form of negative reduction used to analyze the constituent used as a basis for analysis in this study.

The research was to obtain how is the impact of negative questions in semantic negative reductions, identify negative questions in semantic negative reductions based on the developmental category found in sentences, and types of negative questions in semantic negative reductions are largely made by categories. The writer used descriptive method in this research. It means that the writer described and analyzed negative question sentences and then classified the students' errors based on the surface strategy taxonomy and developmental category in negative interrogative sentences. The data collecting technique used are library research and interview. The writer discussed, and then distributed data. All of the data were chosen which coherence with types of negative question.

\section{RESULT AND DISCUSSION}

The impact of negative reduction on negative questions in semantic in this research is to perform the transformation of negative question with some categories and types; Auxiliary Verb and Modal Auxiliary categories. The supporting elements in the negative question is the presence of the auxiliary and the short or negative markers which are not given the markers and emphasize the main verbs but also to produce enough significant. Identify negative questions in semantic negative reductions based on the developmental category found in sentences.

\section{Yes/ No Questions}

In general negative question is a sentence a sentence formed by the adjective either in the auxiliary verb or in the capital and puts the negative note marked in full or abbreviated form in the n't form. Questions that have either "yes" or "no" for an answer are formed using aux -neg at the beginning of the sentence, for example:

a. Neg Aux+s+ main verb+comp to be

"Aren't you aware of the consequences of your actions?"

b. Neg Aux+s+ main verb+comp to do "Don't you have a dollar?"

c. Neg Aux + s+ main verb+comp to have "Haven't you seen my wallet?"

The full note types are found in formal or full contraction and not contraction on data form of an informal type have different meaning and negative assumption, pre assumption negative outdoor and indoor will be appear. The contracted with the negative auxiliary verb, however, then the contraction comes before the subject. Negative question "yes/no questions" usually imply that the speaker expects the answer to be (or believes the answer should be) "yes."

a. To be Neg Aux + s+ main verb+comp

"Are not you aware of the consequences of your actions?"

b. To Do +neg Auxt $+\mathrm{S}+$ main Verb

"Do not you have a dollar?"

c. To Have Neg aux $+\mathrm{S}=$ Complement

"Have not you seen my wallet?"

The formulation rules in terms of structural rather than semantic notions and that the insertion of be forms (is/are) in interrogative sentences is prior to Subject-Aux Inversion.

The function of the main verb in negative question is very influential and capable of forming meaning as shown by the following examples: In the English varieties, negative verb reduction negatively affects the meaning of meaning and allows for the meaning to flow beyond the expected assumption. Some languages display an abbreviated form may have different variations but that is just a variation of the reasoning of some forms of negative form as the main verb, while it may not be miraculous for the most varieties in a typical subject but also theoretically have aux-in-behavior in syntax, may influence inversion of subject in negative questions

\section{"Wh-/ How" Questions}

Negative with interrogative sentences that are formed with certain question words (who, what, where, when, why and How). The relationship between semantic relations and negative reduction in the form of yes-no and assertive forms is quite clear, even though it is visible and appears in the form of utterances this form is very influential in a negative position having 
different syntactic and semantic characteristics which is very interesting to study with Literal questions The negative interrogative is often used literally for sentences with question words.

For example:

a) "It seems like just about everyone is signed up for the trip. Who isn't coming?"

b) "Why haven't we left yet?"

The positive assumption we can find with literal question in each of these sentences, the speaker is asking a question that requires a literal response. Although this is the historical origin of the negative forms, clearly in the modern language the $-n^{\prime} t$ in these words are suffixes forming a single invisible word as the negative auxiliaries display different syntactic behavior compared with constructions consisting of auxiliary + not:

c) Didn't Hery bring the coffee?

*Did not Hery bring the coffee?

d. Shouldn't Halil go to the store?

* Should Halil not go to the store?

e. *He'dn't go to the store if she asked him.

Finally, the negative question as inflection in semantic applies generally to auxiliaries in negative reduction but not to main verbs. There are two exceptions to this, however, involving the "negative question reduction" priority verbs. The function of the main working word in the question negative form is highly influential and able to form the meanings as shown by the following examples on the English variables, negative reduction of the major work affects the meaning that is bound and allows It is hoped that the meaning of the assumption is expected. Some forms in the word cannot be relevant to be abbreviated as this can happen because there are several variants of the language has different variations but it is only a variation of reasoning in the assumption of negative forms as the main verb, while not using grammatical rules for most varieties in a particular language. Theoretically we can indicate the existence of an aux-in other syntax behavior, can affect the subject inversion in the negative questions.

\section{CONCLUSION AND SUGGESTION}

Negative questions in English have some particular forms, categories and meanings, it could refer to different assumptions, both negative and positive. The interpretation meanings are able to give different impact which reduced the negative meaning of negative reduction to produce negative questions in positive meaning. From the previous explanation, there are manipulation meanings from negative questions which given different impact of negative reduction to be positive meaning or even ambiguous. The meaning might also be influenced by interrogative sentence and negative question based on developmental category occurred which is pre- systematic stage. The lacks of knowledge about grammar produced were having several indicators such as insufficient grammar mastery, or lack of knowledge.

In line with the result, it is suggested that English should not ignore the wrong sentence made so that can give provide description for some tasks or exercises which enable them to practice using negative question tenses. Negative question structure is a (usually spoken) form which communicates that you expect a certain answer, that you have already formed an opinion on the subject. Negative question sentence is a virtual communication and interpretation meaning and the function question mark end the end of sentence its very crucial. Kinds of sentences and four types basic in English have explained it. How can your imagination a life without question? So that why Negative question appears and enable as particular information and clear up in interesting conversations with others. It is benefit in semantic meaning as interpretation; for example, people can set up negative questions as conversation and can be response it to explain a concept in more detail.

Referring to the findings previously presented, the writer would like to propose some recommendations as follows: improvements in the negative question and we should be wise and smart to trick this fact, so that it can be valuable input for the success of learning language. It difficult to understand and give more contextual exercise about it. The semantic meaning the summary of the tenses in the table in order to make it easier for the student to be learnt. The material should be arranged from the negative question rules to the more difficult ones. To select the material, the teacher should be concerned how to construct sentences that are grammatically and appropriately correct. It is important to give attention on the common errors (formation errors and presystematic errors) that students produce in their language performance and carefully for the sentences. So that the people can improvements, they can learn from the errors they produced and it is expected that they will not produce the same error repeatedly. It should ask the student to do assignment in the classroom as practice and to do assignment at home as homework. It should be intensively done until the student come to progress.

\section{REFERENCES}

1. Quirk, R. (1985-1990). Comprehensive Grammar of the English Language. UK. Longman.

2. Corder, S. P. (1973). The elicitation of interlanguage. Errata: Papers in error analysis, 36-48.

3. Greenberg. (1997). Question in Handbook of Logic and Language, ed J.Va.

4. Payne, S. L., La Celle, K., Pei, X. F., Qi, X. M., Shao, H., Steagall, W. K., ... \& Fuller, F. (1999). Long terminal repeat sequences of equine 
infectious anaemia virus are a major determinant of cell tropism. Journal of general virology, 80(3), 755-759.

5. Klammer, T. P. (2000). Analyzing English Grammar. Third Edition. California Stages University Fullerton.

6. Downing, A., \& Locke, P. (2006) A University course in English Grammar London McCollum,
G. (1980). 101 Word Games: For Students of English as a Second or Foreign Language. Oxford: Oxford University Press.

7. Radford, A. (1990). Syntactic Theory and the Acquisition of English Syntax. Oxford: Blackwell.

8. Djaja, S. (1993). Linguistic approach method Research method and study Bandung. Eresco. 